\title{
Serum levels of anti-sperm-associated antigen 9 antibody are elevated in patients with hepatocellular carcinoma
}

\author{
BIQIONG REN ${ }^{1-3}$, GUOYING ZOU ${ }^{1-3}$, FEI XU ${ }^{1,2}$, YIRAN HUANG $^{2}$, \\ GUOFENG XU ${ }^{2,3}$, JUNYU HE ${ }^{1-3}$, YONG LI ${ }^{2,3}$, HAOWEN ZHU ${ }^{2,3}$ and PING YU \\ ${ }^{1}$ Clinical Laboratory, Hunan Provincial Second People's Hospital; ${ }^{2}$ Clinical Medical School, \\ Hunan University of Chinese Medicine, Changsha, Hunan $410007 ;{ }^{3}$ Department of Immunology, \\ School of Basic Medicine, Central South University, Changsha, Hunan 410078, P.R. China
}

Received January 24, 2016; Accepted January 19, 2017

DOI: $10.3892 / \mathrm{ol} .2017 .7152$

\begin{abstract}
At present, there is a high incidence of viral hepatitis and high mortality rates due to hepatocellular carcinoma (HCC) in China. In the current study, the quantification of antibodies against the cancer-testis antigen sperm-associated antigen 9 (SPAG9), alone and combined with $\alpha$-fetoprotein (AFP), were evaluated as biomarkers for the diagnosis of HCC. The levels of anti-SPAG9 antibody and AFP were quantified in serum samples from patients with HCC and hepatitis or cirrhosis, as well as healthy volunteers. The results revealed that the serum levels of anti-SPAG9 immunoglobulin $\mathrm{G}$ antibody in patients with $\mathrm{HCC}$ were significantly higher compared with those in patients with hepatitis/cirrhosis and healthy controls. Using receiver operator characteristic curves, the area under the curve (AUC, 0.870) of SPAG9 as a diagnostic marker of $\mathrm{HCC}$ was significant $[\mathrm{P}<0.001$; 95\% confidence interval (CI), 0.793-0.947], whereas the AUC of AFP was 0.832 ( $\mathrm{P}<0.001 ; 95 \%$ CI, 0.736-0.928). Serum anti-SPAG9 antibody levels exhibited significant potential for the differential diagnosis of $\mathrm{HCC}$, with an AUC value of 0.729 , ( $\mathrm{P}=0.008$; 95\% CI, 0.559-0.899). Similarly, serum AFP levels exhibited significant value for the differential diagnosis of $\mathrm{HCC}$, with an AUC value of 0.842 ( $\mathrm{P}<0.001 ; 95 \%$ CI, 0.732-0.953). When combined with quantification of AFP, the diagnostic sensitivity and specificity of anti-SPAG9 levels were increased. In summary, the results suggested that anti-SPAG9 antibody is a potential early diagnostic marker of HCC.
\end{abstract}

Correspondence to: Professor Biqiong Ren, Clinical Laboratory, Hunan Provincial Second People's Hospital, 427 Furong Road, Changsha, Hunan 410007, P.R. China

E-mail: 13808481211@163.com

Abbreviations: SPAG9, sperm-associated antigen 9; HCC, hepatocellular carcinoma; AFP, $\alpha$-fetoprotein; CTA, cancer-testis antigen; $\mathrm{HBV}$, hepatitis B virus; $\mathrm{HCV}$, hepatitis $\mathrm{C}$ virus; $\mathrm{DCP}$, des-gamma-carboxy-prothrombin; ROC, receiver operator characteristic

Key words: sperm-associated antigen 9, autoantibody, biomarker, hepatocellular carcinoma, diagnosis

\section{Introduction}

Hepatitis B virus (HBV) and hepatitis C virus (HCV) infections are major risk factors for the development of human hepatocellular carcinoma (HCC) (1-3). The incidence of HCC in China is $\sim 100 / 100,000$ population, and a principal component of the attributable risk is chronic HBV infection (4), with $>50 \%$ of the global HCC burden attributed to HBV (5). In China, $\sim 10 \%$ of patients with $\mathrm{HCC}$ suffer from $\mathrm{HCV}$ infection, and certain patients have HBV and HCV co-infections (6). In the USA, Europe and Japan, $>50 \%$ of current cases of HCC are attributable to $\mathrm{HCV}$ infection, and the majority of these patients have cirrhosis (7-9). The time from initial diagnosis of chronic hepatitis to the development of HCC may span several decades; once cirrhosis is established, HCC develops at a yearly rate of $1-4 \%(10)$.

In China, the majority of patients with HCC present with advanced-stage disease, and HCC has become the second leading cause of mortality (11). Early diagnosis relies on non-invasive biomarkers, imaging and clinical parameters, with markers such as $\alpha$-fetoprotein (AFP), the proportion of the fucosylated isoform of AFP to total AFP, AFP-L3 and des-gamma-carboxy-prothrombin (DCP) being Food and Drug Administration-approved for use in the surveillance of high-risk populations $(12,13)$. However, the clinical value of these biomarkers is a subject of debate (14). In Japan, three biomarkers are combined for surveillance $(15,16)$, and this combined testing has a high level of sensitivity and specificity $(17,18)$. In China, AFP is the only serum biomarker routinely used for HCC diagnosis (19). Up to $50 \%$ of patients with HCC have a serum AFP level of $<20 \mathrm{ng} / \mathrm{ml}$ (20), and therefore are not correctly diagnosed when AFP is the sole biomarker used to screen for HCC (21).

In the current study, the efficacy of the cancer-testis antigen (CTA) sperm-associated antigen 9 (SPAG9), alone and combined with AFP, was evaluated for use in the diagnosis of $\mathrm{HCC}$ caused by HBV or HCV infections.

CTAs include the melanoma antigen family, the synovial sarcoma $\mathrm{X}$ family, cancer/testis antigen 2, G antigen 1 , cancer/testis associated protein CTp11 and cancer/testis antigen 1B. The expression of these antigens is normally restricted to the testis, but these antigens are also expressed 
in tumor tissues (22-24). Several studies have revealed that CTAs are highly expressed in the tumor tissue of patients with HCC (25-27). SPAG9 belongs to the c-Jun- $\mathrm{NH}_{2}$ terminal kinase-interacting protein family (28). Proteins from this family function in cell growth, proliferation, apoptosis and tumor development $(29,30)$, and are expressed in renal cell carcinoma, and ovarian, cervical, breast, thyroid and colorectal cancer tissues, SPAG9 provokes a strong humoral immune response, and its autoantibody can be detected in the peripheral blood of patients with the aforementioned types of cancer (21-35). The current study hypothesized that anti-SPAG9 antibody may be detected in the peripheral blood of patients with HCC, and that, in combination with serum AFP levels, it may provide a reliable diagnostic test for HCC, particularly for AFP-negative patients.

\section{Materials and methods}

Patients. A total of 31 cases of HCC caused by HBV or HCV infections, 41 cases of hepatitis or cirrhosis caused by HBV or HCV without HCC, and 37 normal healthy blood donors were enrolled at Hunan Provincial Second People's Hospital (Changsha, China) from March 2013 to May 2014. HCC was diagnosed as previously reported (18). The inclusion criteria were no prior anti-cancer treatment (therapeutic agents, radiotherapy or chemotherapy) and positivity for $\mathrm{HBV}$ or $\mathrm{HCV}$ infection. The exclusion criteria were as follows: Active liver disease (non-cancerous hepatitis or cirrhosis), pregnancy, reproductive system embryonic tumors or metastatic liver cancer. The cases with hepatitis or cirrhosis without HCC included eight patients with cirrhosis. Patient characteristics are summarized in Tables I and II. Peripheral blood samples were collected from patients and controls. Serum was separated by centrifuging blood at $1,000 \mathrm{x}$ g for $10 \mathrm{~min}$ at $25^{\circ} \mathrm{C}$. Serum samples were stored at $-80^{\circ} \mathrm{C}$ prior to analysis.

SPAG9 ELISA assay. Recombinant human SPAG9 protein (r-hSPAG9; Abnova, Taipei, Taiwan) was used as antigen to establish an ELISA to detect serum anti-SPAG9 immunoglobulin IgG antibody. Microtiter plates were coated with r-hSPAG9 (100 ng/well) in $50 \mathrm{mM}$ PBS (pH 7.4) at $4^{\circ} \mathrm{C}$ overnight. The plates were washed three times with PBS and blocked with $5 \%$ bovine serum albumin (Zhejiang Tianhang Biotechnology Co., Ltd, Huzhou, China) in PBS for $2 \mathrm{~h}$ at $37^{\circ} \mathrm{C}$. Post-blocking, the plates were incubated with a 1:10 dilution (0.05 M carbonate buffer, $\mathrm{pH}$ 9.6) of patient serum. Bound antibodies were detected after incubation with a mouse anti-human antibody conjugated to horseradish peroxidase (Beijing Beier Biological Engineering Co., Ltd., Beijing, China; cat. no. 20141001) at an optimized dilution of 1:5,000 in PBS for $2 \mathrm{~h}$ at $37^{\circ} \mathrm{C}$. Enzyme activation was performed with $0.05 \%$ orthophenylenediamine (Beijing Beier Biological Engineering Co., Ltd.) in $50 \mathrm{mM}$ citrate phosphate buffer ( $\mathrm{pH} 5.0$ ) with $0.06 \%$ hydrogen peroxide as the substrate. The reaction was terminated with $50 \mu 1$ of $5 \mathrm{M}$ $\mathrm{H}_{2} \mathrm{SO}_{4}$, and the absorbance was read at a wavelength of $450 \mathrm{~nm}$ using a microplate spectrophotometer with $630 \mathrm{~nm}$ as a reference filter. The intra- and inter-assay coefficients of variation were 2.3 and $8.6 \%$, respectively.

AFP chemiluminescence assay. Serum AFP levels were determined using the ADVIA Centaur XP Immunoassay
System (Siemens AG, Munich, Germany), and the quality control materials were provided by Bio-Rad Laboratories, Inc. (Hercules, CA, USA).

Statistical analysis. The Kruskal-Wallis, Mann-Whitney $\mathrm{U}$, independent-samples $\mathrm{t}$ and $\chi^{2}$ tests, as well as receiver operator characteristic (ROC) curve analysis were performed using SPSS version 16.0 (SPSS, Inc., Chicago, IL, USA). Results were presented as the mean \pm standard deviation. Anti-SPAG9 antibody levels in patients with $\mathrm{HCC}$, patients with hepatitis/cirrhosis and healthy individuals were compared using the Mann-Whitney U test with Bonferroni correction. $\alpha=0.0167$ and $\mathrm{P}<0.0167$ were considered to indicate a statistically significant difference. Positivity of anti-SPAG9 antibody in patients with HCC, patients with hepatitis/cirrhosis and healthy individuals was compared using the $\chi^{2}$ test and partitioned $\chi^{2}$ tests. $\alpha=0.0125$ and $\mathrm{P}<0.0125$ were considered to indicate a statistically significant difference. The percentages of patients who were positive for a marker were compared using a $\chi^{2}$ test with an inspection level of 0.05 considered to indicate a statistically significant difference. For multiple comparisons, the $\chi^{2}$ test was used, with an inspection level corrected to 0.0125 considered to indicate a statistically significant difference. For other comparisons performed with an independent-samples t test, $\mathrm{P}<0.05$ was considered to indicate a statistically significant difference.

\section{Results}

Levels of serum anti-SPAG9 antibody in patients with HCC and hepatitis/cirrhosis. The mean of the signal intensity in the SPAG9 ELISA for patients with HCC $(0.590 \pm 0.274)$ was significantly higher than that for patients with hepatitis/cirrhosis $(0.445 \pm 0.515)$ and healthy individuals $(0.189 \pm 0.115 ; \mathrm{P}<0.001)$. Data from all patients and individuals are plotted in Fig. 1A. Using a cut-off value of $0.42,71.0 \%$ of the patients with HCC were positive for the SPAG9 antigen, whereas $26.8 \%$ of patients with hepatitis/cirrhosis and $8 \%$ of healthy individuals were positive for the antigen based on this cut-off (Fig. 1B). The mean absorbance $(0.89 \pm 0.810)$ of anti-SPAG9 immunoglobulin IgG antibody in patients with cirrhosis was significantly higher compared with that of patients with hepatitis $(0.337 \pm 0.355)$ and healthy individuals $(\mathrm{P}<0.001$; Fig. $1 \mathrm{C})$.

Levels of serum anti-SPAG9 antibody in patients with various stages of HCC. The mean of the signal intensity in the SPAG9 ELISA in patients with stage II HCC $(0.647 \pm 0.310)$ was significantly higher $(\mathrm{P}<0.01)$ compared with that in patients with stage III and IV disease $(0.468 \pm 0.153$; Fig. 2A). Of the stage II patients with HCC, $75 \%$ were positive for SPAG9, whereas $63.6 \%$ of stage III and IV patients were positive for SPAG9 (Fig. 2B). This difference was not significant.

Sensitivity and specificity of anti-SPAG9 antibody alone and in combination with AFP for HCC diagnosis. The sensitivity and specificity of anti-SPAG9 antibody alone for the diagnosis of HCC were 71.0 and $87.3 \%$, respectively. The sensitivity was higher compared with that of AFP alone (64.5\%), whereas the specificity was lower compared with that of AFP alone 
Table I. Characteristics of patients with HCC, hepatitis or cirrhosis and healthy controls.

\begin{tabular}{lccc}
\hline Patient characteristic & HCC $(\mathrm{n}=31)$ & Hepatitis/cirrhosis $(\mathrm{n}=41)$ & Healthy controls $(\mathrm{n}=35)$ \\
\hline Age, years & & & \\
Mean \pm SD (min, max) & $56 \pm 12(36,76)$ & $41 \pm 16(21,77)$ & $53 \pm 10(26,71)$ \\
Sex & & & $74.9(34 / 41)$ \\
Male, \% (n/total) & $83.9(26 / 31)$ & $17.1(7 / 41)$ & $25.7(9 / 35)$ \\
Female, \% (n/total) & $16.1(5 / 31)$ & & \\
Cancer stage & $64.5(20 / 31)$ & 36 & 0 \\
II, \% (n/total) & $35.5(11 / 31)$ & 5 & 0 \\
II + IV, \% (n/total) & 28 & & \\
Hepatitis B infection, $n$ & 3 & & \\
Hepatitis C infection, $n$ & & & \\
\hline
\end{tabular}

SD, standard deviation; HCC, hepatocellular carcinoma; min, minimum; max, maximum.

Table II. Characteristics of patients with hepatitis and cirrhosis and healthy controls.

\begin{tabular}{lccc}
\hline Patient characteristic & Hepatitis $(\mathrm{n}=33)$ & Cirrhosis $(\mathrm{n}=8)$ & Healthy controls $(\mathrm{n}=35)$ \\
\hline Age, years & & & $53 \pm 10(26,71)$ \\
Mean \pm SD (min, max) & $41 \pm 13(21,65)$ & $55 \pm 12(32,77)$ & $74.3(26 / 35)$ \\
Sex & & & $25.7(9 / 35)$ \\
Male, \% (n/total) & $81.8(27 / 33)$ & $12.5(1 / 8)$ & 0 \\
Female, \% (n/total) & $18.2(6 / 33)$ & 8 & 0 \\
Hepatitis B infection, $n$ & 28 & 0 & 0 \\
Hepatitis C infection, $n$ & 5 & & \\
\hline
\end{tabular}

$\mathrm{SD}$, standard deviation; min, minimum; max, maximum.
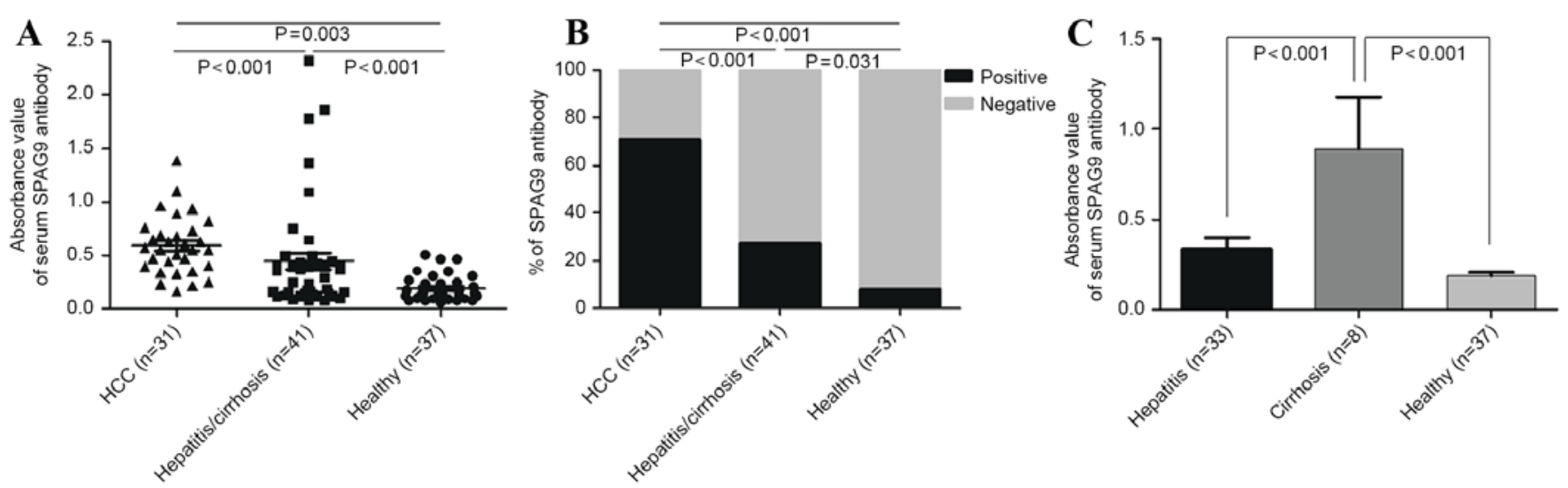

Figure 1. (A) Anti-SPAG9 antibody in the serum of patients with HCC ( $\mathrm{n}=31)$, patients with hepatitis or cirrhosis $(\mathrm{n}=41)$ and healthy controls $(\mathrm{n}=37)$, as detected using ELISA. (B) Percentage of patients and healthy controls positive for anti-SPAG9 antibody. (C) Anti-SPAG9 antibody in serum of patients with cirrhosis $(n=8)$, patients with hepatitis $(n=33)$ and healthy controls $(n=37)$, as detected by ELISA. SPAG9, sperm-associated antigen 9; HCC, hepatocellular carcinoma.

(94.5\%). When anti-SPAG9 and AFP were used in parallel, the sensitivity and specificity were 90.3 and $83.6 \%$, respectively. In series, with the anti-SPAG9 antibody test conducted first, the sensitivity and specificity were 45.2 and $98.2 \%$, respectively (Table III). The ROC curve for serum anti-SPAG9 antibody had an AUC value of $0.870[\mathrm{P}<0.001 ; 95 \%$ confidence interval
(CI), 0.793-0.947]. The ROC curve for AFP had an AUC value of 0.832 ( $\mathrm{P}<0.001 ; 95 \%$ CI, 0.736-0.928; Fig. 3A).

The sensitivity and specificity of anti-SPAG9 antibody alone in the differential diagnosis of HCC were 71.0 and $77.8 \%$, which was higher in sensitivity and lower in specificity than the value obtained for AFP alone (64.5 and 83.3\%, respectively). 
Table III. Diagnostic value of anti-SPAG9 alone and in combination with AFP.

\begin{tabular}{|c|c|c|c|c|c|c|c|}
\hline Item & Sensitivity, \% & Specificity, \% & PPV, \% & NPV, $\%$ & $\begin{array}{l}\text { Positive } \\
\text { likelihood } \\
\text { ratio }\end{array}$ & $\begin{array}{l}\text { Negative } \\
\text { likelihood } \\
\text { ratio }\end{array}$ & $\begin{array}{c}\text { Youden } \\
\text { index, } \%\end{array}$ \\
\hline Anti-SPAG9 antibody & 71.0 & 87.3 & 75.9 & 84.2 & 5.58 & 0.33 & 58.2 \\
\hline AFP & 64.5 & 94.5 & 87.0 & 82.5 & 11.83 & 0.38 & 59.1 \\
\hline Parallel use & 90.3 & 83.6 & 75.7 & 93.9 & 5.52 & 0.12 & 74.0 \\
\hline Series use (anti-SPAG9, then AFP) & 45.2 & 98.2 & 93.3 & 76.1 & 24.84 & 0.56 & 43.3 \\
\hline
\end{tabular}

SPAG9, sperm-associated antigen 9; AFP, $\alpha$-fetoprotein; PPV, positive predictive value; NPV, negative predictive value.
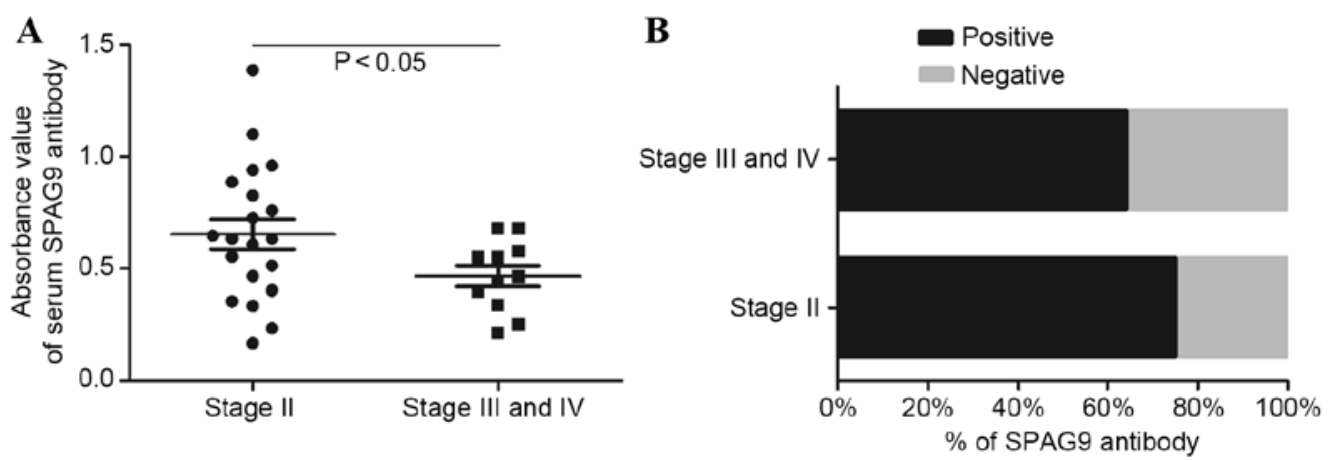

Figure 2. (A) Anti-SPAG9 antibody in the serum of patients with stage II and with stage III or IV HCC, as detected using ELISA. (B) Percentage of patients with stage II or with stage III and IV HCC that were seropositive for anti-SPAG9 antibody. SPAG9, sperm-associated antigen 9; HCC, hepatocellular carcinoma
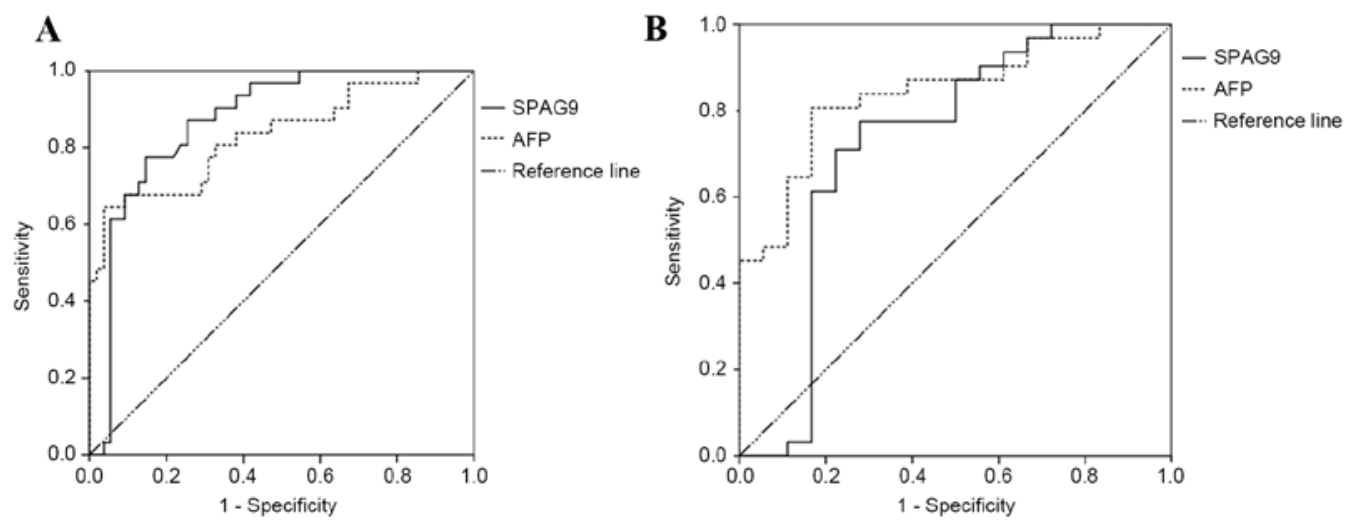

Figure 3. (A) ROC curve analysis of the levels of serum anti-SPAG9 antibody and AFP for the diagnosis of HCC. (B) ROC curve analysis of the levels of serum anti-SPAG9 antibody and AFP to obtain a differential diagnosis of HCC. ROC; receiver operator characteristic; SPAG9, sperm-associated antigen 9; AFP, $\alpha$-fetoprotein; HCC, hepatocellular carcinoma.

A combination of anti-SPAG9 antibody with AFP in parallel obtained a sensitivity and specificity of differential diagnosis of 90.3 and $66.7 \%$, respectively. When anti-SPAG9 antibody and AFP were used in series, the sensitivity and specificity of diagnosis were 45.2 and $94.4 \%$, respectively (Table IV). ROC curves for serum anti-SPAG9 antibody had an AUC value of 0.729 ( $\mathrm{P}<0.001 ; 95 \%$ CI, 0.559-0.899). The ROC curve for AFP had an AUC value of 0.842 (P<0.001; 95\% CI, 0.732-0.953; Fig. 3B). HCC and with hepatitis/cirrhosis. Anti-SPAG9 antibodies were detected in $71.0 \%$ of patients with $\mathrm{HCC}$, whereas AFP was detected in $64.6 \%$ of patients; this difference was not significant $(\mathrm{P}<0.05)$. Of patients with hepatitis or cirrhosis, $26.8 \%$ tested positive for anti-SPAG9, whereas $13 \%$ were positive for AFP, and this difference was significant $(\mathrm{P}<0.01)$. In healthy controls, $8.0 \%$ had serum antibodies against SPAG9 and 3.0\% expressed AFP (Figs. 1B and 4). The proportion of male patients with HCC that were positive for serum anti-SPAG9 antibody was significantly lower than the proportion of female patients. By contrast, male patients with HCC were more likely to test positive for serum AFP compared with female patients (Fig. 5). 
Table IV. Differential diagnostic value of anti-SPAG9 alone and in combination with AFP.

\begin{tabular}{|c|c|c|c|c|c|c|c|}
\hline Item & Sensitivity, \% & Specificity, $\%$ & PPV, \% & NPV, \% & $\begin{array}{l}\text { Positive } \\
\text { likelihood } \\
\text { ratio }\end{array}$ & $\begin{array}{l}\text { Negative } \\
\text { likelihood } \\
\text { ratio }\end{array}$ & $\begin{array}{c}\text { Youden } \\
\text { index, } \%\end{array}$ \\
\hline Anti-SPAG9 antibody & 71.0 & 77.8 & 84.6 & 60.9 & 3.19 & 0.37 & 48.7 \\
\hline AFP & 64.5 & 83.3 & 87.0 & 57.7 & 3.87 & 0.43 & 47.8 \\
\hline Parallel use & 90.3 & 66.7 & 82.4 & 80.0 & 2.71 & 0.15 & 57.0 \\
\hline Series use (anti-SPAG9, then AFP) & 45.2 & 94.4 & 93.3 & 50.0 & 8.13 & 0.58 & 39.6 \\
\hline
\end{tabular}

SPAG9, sperm-associated antigen 9; AFP, $\alpha$-fetoprotein; PPV, positive predictive value; NPV, negative predictive value.

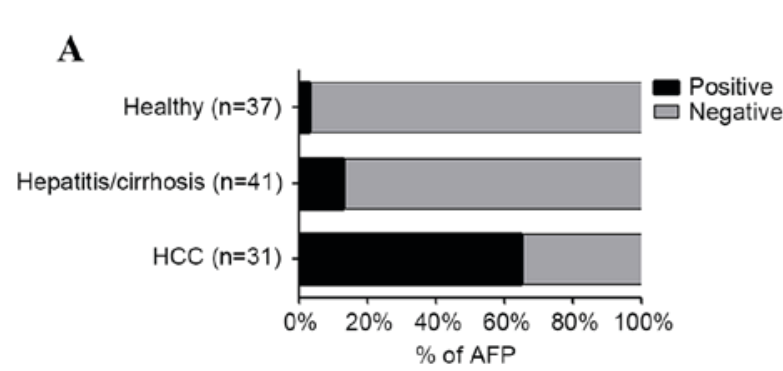

B

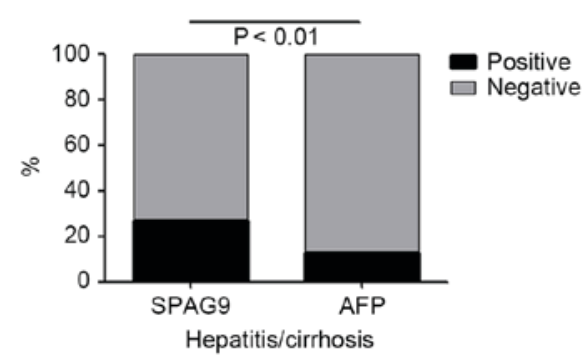

Figure 4. (A) Percentage of patients with HCC, hepatitis or cirrhosis and healthy controls that were seropositive for AFP. (B) Percentage of patients with hepatitis and cirrhosis that were seropositive for SPAG9 antibody and AFP. HCC, hepatocellular carcinoma; SPAG9, sperm-associated antigen 9; AFP, $\alpha$-fetoprotein.

\section{Discussion}

China is a country with a high incidence of viral hepatitis and high mortality rates due to HCC. In China, AFP is the only serum biomarker included in the diagnostic criteria for HCC, whereas other countries suggest the use of a combination of non-invasive biomarkers for surveillance in high-risk populations. At present, AFP is the most effective diagnostic indicator for HCC (36). A recent meta-analysis of the diagnostic value of AFP in HCC determined a pooled sensitivity of $66 \%$, a specificity of $86 \%$ and an AUC value of 0.87 (37). The combination of AFP with DCP produced a sensitivity of $55 \%$ for the detection of early-stage HCC and $78 \%$ for the diagnosis of all stages of HCC, with cut-off values of $10 \mathrm{ng} / \mathrm{ml}$ for AFP and $5 \mathrm{ng} / \mathrm{ml}$ for DCP (38). The addition of AFP-L3 led to a further enhancement in sensitivity to $84 \%$ (39).

Anti-CTA antibodies are generally absent or present at a low frequency in healthy individuals, but are highly expressed by patients with cancer $(40,41)$. The current study therefore

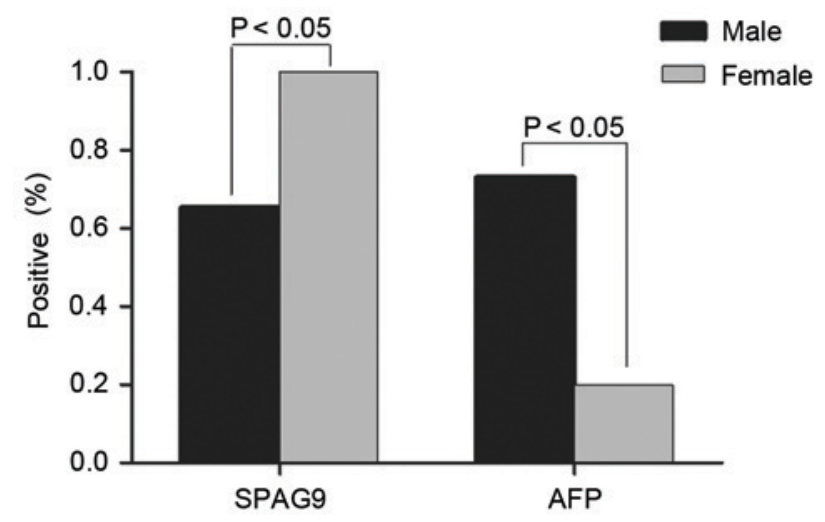

Figure 5. Percentage of male and female patients with hepatocellular carcinoma that were seropositive for SPAG9 and AFP. SPAG9, sperm-associated antigen 9; AFP, $\alpha$-fetoprotein.

hypothesized that a CTA may serve as a biomarker for HCC. The results revealed that the serum levels of anti-SPAG9 antibody had a diagnostic sensitivity of $71.0 \%$, a specificity of $87.3 \%$ and an AUC value of 0.870 in patients with HCC. The combination of AFP with anti-SPAG9 antibody in parallel had a sensitivity of $90.3 \%$; in series, the specificity was $98.2 \%$. The level of serum anti-SPAG9 antibody was significantly higher in patients with HCC than in patients with hepatitis or cirrhosis and healthy controls. In addition, the serum anti-SPAG9 levels were significantly higher in patients with stage II HCC compared with those in patients with stage III or IV disease. These data indicate that anti-SPAG9 is a potential early diagnostic marker for HCC. As the current study evaluated a small cohort of patients, analyses of larger numbers of patients are required.

The liver is a sexually dimorphic organ, with sex variations in mitochondrial function, membrane lipid composition, microsomal enzyme activity, gene expression and immune responses (42). Sexual dimorphism of the liver alters the metabolism of drugs and toxins in males and females (43). This may at least partially explain the observed sex differences in anti-SPAG9 antibody expression in patients with HCC. In the current study, the proportion of male patients with HCC that were positive for serum anti-SPAG9 antibody was significantly lower compared with the proportion of female patients. By contrast, male patients with HCC were more likely to test positive for serum AFP compared with 
female patients. However, the number of female patients included in the present study was lower than the number of male patients, and further research requires an expansion in the study population.

Chronic hepatitis and cirrhosis are common precursor conditions of HCC. During the process of transition to malignancy, certain patients may develop autoantibodies that were not present during the precursory chronic liver disease phase (44). In the present study, the level of anti-SPAG9 IgG antibody in patients with cirrhosis was significantly higher compared with that in patients with hepatitis and healthy controls. This suggests that the strong humoral immune response triggered by SPAG9 in patients with cirrhosis may be an early marker for carcinogenesis. A greater number of patients with cirrhosis tested positive for SPAG9 compared with those who tested positive for AFP, indicating that the humoral immune response to SPAG9 may be an effective marker for early screening in populations with a high risk for HCC.

In conclusion, anti-SPAG9 antibody levels in the peripheral blood of patients with HCC were significantly higher compared with those in patients with hepatitis or cirrhosis and healthy controls. The potential value of SPAG9 as a diagnostic marker for $\mathrm{HCC}$ requires further investigation. Combining serum anti-SPAG9 antibody and AFP as disease markers may allow the early diagnosis of HCC.

\section{Acknowledgements}

The present study was supported by a research grant from the Health Department of Hunan Province Foundation (grant no. B2011-099) and the Second People's Hospital of Hunan Province Key Specialized Foundation (grant no. 2014-005).

\section{References}

1. Dhanasekaran R, Limaye A and Cabrera R: Hepatocellular carcinoma: Current trends in worldwide epidemiology, risk factors, diagnosis, and therapeutics. Hepat Med 4: 19-37, 2012.

2. Raimondi S, Bruno S, Mondelli MU and Maisonneuve P: Hepatitis $\mathrm{C}$ virus genotype $1 \mathrm{~b}$ as a risk factor for hepatocellular carcinoma development: A meta-analysis. J Hepatol 50 $1142-1154,2009$

3. Pollicino T, Squadrito G, Cerenzia G, Cacciola I, Raffa G, Craxi A, Farinati F, Missale G, Smedile A, Tiribelli C, et al: Hepatitis B virus maintains its pro-oncogenic properties in the case of occult HBV infection. Gastroenterology 126: 102-110, 2004.

4. Sherman M: Hepatocellular carcinoma: Epidemiology, risk factors, and screening. Semin Liver Dis 25: 143-154, 2005.

5. Parkin DM: The global health burden of infection-associated cancers in the year 2002. Int J Cancer 118: 3030-3044, 2006

6. Song P, Feng X, Zhang K, Song T, Ma K, Kokudo N, Dong J, Yao $L$ and Tang W: Screening for and surveillance of high-risk patients with HBV-related chronic liver disease: Promoting the early detection of hepatocellular carcinoma in China. Biosci Trends 7: 1-6, 2013.

7. Kiyosawa K, Umemura T, Ichijo T, Matsumoto A, Yoshizawa K, Gad A and Tanaka E: Hepatocellular carcinoma. Recent trends in Japan. Gastroenterology 127 (5 Suppl 1): S17-S26, 2004.

8. Di Bisceglie AM, Lyra AC, Schwartz M, Reddy RK, Martin P, Gores G, Lok AS, Hussain KB, Gish R, Van Thiel DH, et al: Hepatitis C-related hepatocellular carcinoma in the United States: Influence of ethnic status. Am J Gastroenterol 98: 2060-2063, 2003.

9. Donato F, Tagger A, Chiesa R, Ribero ML, Tomasoni V, Fasola M, Gelatti U, Portera G, Boffetta P and Nardi G: Hepatitis B and C virus infection, alcohol drinking, and hepatocellular carcinoma: A case-control study in Italy. Brescia HCC study. Hepatology 26: $579-584,1997$.
10. Fattovich G, Giustina G, Degos F, Tremolada F, Diodati G, Almasio P, Nevens F, Solinas A, Mura D, Brouwer JT, et al: Morbidity and mortality in compensated cirrhosis type C: A retrospective follow-up study of 384 patients. Gastroenterology 112: 463-472, 1997.

11. Kudo M, Han KH, Kokudo N, Cheng AL, Choi BI, Furuse J, Izumi N, Park JW, Poon RT and Sakamoto M: Liver cancer working group report. Jpn J Clin Oncol 1 (Suppl 40): i19-i27, 2010.

12. Bruix J and Sherman M; American Association for the Study of Liver Diseases: Management of hepatocellular carcinoma: An update. Hepatology 53: 1020-1022, 2011.

13. European Association for the Study of the Liver; European Organisation for Research and Treatment of Cancer: EASL-EORTC clinical practice guidelines: Management of hepatocellular carcinoma. J Hepatol 56: 908-943, 2012.

14. Bruix J, Gores GJ and Mazzaferro V: Hepatocellular carcinoma: Clinical frontiers and perspectives. Gut 63: 844-855, 2014.

15. Omata M, Lesmana LA, Tateishi R, Chen PJ, Lin SM, Yoshida H, Kudo M, Lee JM, Choi BI, Poon RT, et al: Asian pacific association for the study of the liver consensus recommendations on hepatocellular carcinoma. Hepatol Int 4: 439-474, 2010.

16. Makuuchi M, Kokudo N, Arii S, Futagawa S, Kaneko S, Kawasaki S, Matsuyama Y, Okazaki M, Okita K, Omata M, et al: Development of evidence-based clinical guidelines for the diagnosis and treatment of hepatocellular carcinoma in Japan. Hepatol Res 38: 37-51, 2008.

17. Song PP, Gao JJ, Kokudo N, Dong JH and Tang W: 'Knowledge into action' exploration of an appropriate approach for constructing evidence-based clinical practice guidelines for hepatocellular carcinoma. Biosci Trends 6: 147-152, 2012.

18. Song P, Gao J, Inagaki Y, Kokudo N, Hasegawa K, Sugawara Y and Tang W: Biomarkers: Evaluation of screening for and early diagnosis of hepatocellular carcinoma in Japan and China. Liver Cancer 2: 31-39, 2013.

19. Song P, Tobe RG, Inagaki Y, Kokudo N, Hasegawa K, Sugawara $Y$ and Tang W: The management of hepatocel-lular carcinoma around the world: A comparison of guidelines from 2001 to 2011. Liver Int 32: 1053-1063, 2012.

20. Farinati F, Marino D, De Giorgio M, Baldan A, Cantarini M, Cursaro C, Rapaccini G, Del Poggio P, Di Nolfo MA, Benvegnù L, et al: Diagnostic and prognostic role of alpha-fetoprotein in hepatocellular carcinoma: Both or neither? Am J Gastroenterol 101: 524-532, 2006.

21. Cui Z, Yu X, Guo L, Wei Y, Zheng S, Li W, Chen P, Zhu J and Peng J: Combined analysis of serum alpha-fetoprotein and MAGE-A3-specific cytotoxic T lymphocytes in peripheral blood for diagnosis of hepatocellular carcinoma. Dis Markers 35: 915-923, 2013.

22. Suri A: Cancer testis antigens-their importance in immunotherapy and in the early detection of cancer. Expert Opin Biol Ther 6: 379-389, 2006

23. Grizzi F, Mirandola L, Qehajaj D, Cobos E, Figueroa JA and Chiriva-Internati M: Cancer-testis antigens and immunotherapy in the light of cancer complexity. Int Rev Immunol 34: 143-153, 2015.

24. Song MH, Choi KU, Shin DH, Lee CH and Lee SY: Identification of the cancer/testis antigens AKAP3 and CTp11 by SEREX in hepatocellular carcinoma. Oncol Rep 28: 1792-1798, 2012.

25. Peng JR, Chen HS, Mou DC, Cao J, Cong X, Qin LL, Wei L, Leng XS, Wang Y and Chen WF: Expression of cancer/testis (CT) antigens in Chinese hepatocellular carcinoma and its correlation with clinical parameters. Cancer Lett 219: 223-232, 2005.

26. Wang Y, Han KJ, Pang XW, Vaughan HA, Qu W, Dong XY, Peng JR, Zhao HT, Rui JA, Leng XS, et al: Large scale identification of human hepatocellular carcinoma-associated antigens by autoantibodies. J Immunol 169: 1102-1109, 2002.

27. Yang XA, Dong XY, Qiao H, Wang YD, Peng JR, Li Y, Pang XW, Tian $C$ and Chen WF: Immunohistochemical analysis of the expression of FATE/BJ-HCC-2 antigen in normal and malignant tissues. Lab Invest 85: 205-213, 2005.

28. Garg M, Chaurasiya D, Rana R, Jagadish N, Kanojia D, Dudha N, Kamran N, Salhan S, Bhatnagar A, Suri S, et al: Sperm-associated antigen 9, a novel cancer testis antigen, is a potential target for immunotherapy in epithelial ovarian cancer. Clin Cancer Res 13: 1421-1428, 2007.

29. Jagadish N, Rana R, Mishra D, Kumar M and Suri A: Sperm associated antigen 9 (SPAG9): A new member of c-Jun NH2-terminal kinase (JNK) interacting protein exclusively expressed in testis. Keio J Med 54: 66-71, 2005. 
30. Yi F, Ni W, Liu W, Pan X, Han X, Yang L, Kong X, Ma R and Chang R: SPAG9 is overexpressed in human astrocytoma and promotes cell proliferation and invasion. Tumour Biol 34: 2849-2855, 2013.

31. Garg M, Kanojia D, Khosla A, Dudha N, Sati S, Chaurasiya D, Jagadish N, Seth A, Kumar R, Gupta S, et al: Sperm-associated antigen 9 is associated with tumor growth, migration, and invasion in renal cell carcinoma. Cancer Res 68: 8240-8248, 2008

32. Garg M, Kanojia D, Salhan S, Suri S, Gupta A, Lohiya NK and Suri A: Sperm-associated antigen 9 is a biomarker for early cervical carcinoma. Cancer 115: 2671-2683, 2009.

33. Kanojia D, Garg M, Gupta S, Gupta A and Suri A: Sperm-associated antigen 9, a novel biomarker for early detection of breast cancer. Cancer Epidemiol Biomarkers Prev 18: 630-639, 2009.

34. Garg M, Kanojia D, Suri S, Gupta S, Gupta A and Suri A: Sperm-associated antigen 9: A novel diagnostic marker for thyroid cancer. J Clin Endocrinol Metab 94: 4613-4618, 2009.

35. Kanojia D, Garg M, Gupta S, Gupta A and Suri A: Sperm-associated antigen 9 is a novel biomarker for colorectal cancer and is involved in tumor growth and tumorigenicity. Am J Pathol 178: 1009-1020, 2011.

36. Yao M, Zhao J and Lu F: Alpha-fetoprotein still is a valuable diagnostic and prognosis predicting biomarker in hepatitis B virus infection-related hepatocellular carcinoma. Oncotarget 7: 3702-3708, 2016.
37. Wan HG, Xu H, Gu YM, Wang H, Xu W and Zu MH: Comparison osteopontin vs. AFP for the diagnosis of HCC: A meta-analysis. Clin Res Hepatol Gastroenterol 38: 706-714, 2014.

38. Ertle JM, Heider D, Wichert M, Keller B, Kueper R, Hilgard P, Gerken G and Schlaak JF: A combination of $\alpha$-fetoprotein and des- $\gamma$-carboxy prothrombin is superior in detection of hepatocellular carcinoma. Digestion 87: 121-131, 2013.

39. Hadziyannis E, Sialevris K, Georgiou A and Koskinas J: Analysis of serum $\alpha$-fetoprotein-L3\% and des- $\gamma$ carboxyprothrombin markers in cases with misleading hepatocellular carcinoma total $\alpha$-fetoprotein levels. Oncol Rep 29: 835-839, 2013.

40. Tan EM: Autoantibodies as reporters identifying aberrant cellular mechanisms in tumorigenesis. J Clin Invest 108: 1411-1415, 2001.

41. Tan EM and Zhang J: Autoantibodies to tumor-associated antigens: Reporters from the immune system. Immunol Rev 222: 328-340, 2008.

42. Dhir RN, Dworakowski W, Thangavel C and Shapiro BH: Sexually dimorphic regulation of hepatic isoforms of human cytochrome p450 by growth hormone. J Pharmacol Exp Ther 316: 87-94, 2006.

43. Waxman DJ and Holloway MG: Sex differences in the expression of hepatic drug metabolizing enzymes. Mol Pharmacol 76: 215-228, 2009

44. Zhang JY, Zhu W, Imai H, Kiyosawa K, Chan EK and Tan EM: De-novo humoral immune responses to cancer-associated autoantigens during transition from chronic liver disease to hepatocellular carcinoma. Clin Exp Immunol 125: 3-9, 2001. 